\title{
Technology Planning through Technology Roadmap: Application of Patent Citation Network
}

\author{
Yujin Jeong ${ }^{1}$ and Byungun Yoon ${ }^{1^{*}}$ \\ ${ }^{1}$ Department of Industrial \& Systems Engineering, Dongguk University \\ 기술로드맵을 통한 기술기획: 특허인용네트워크의 활용 \\ 정유진 ${ }^{1}$, 윤병운 ${ }^{*}$ \\ ${ }^{1}$ 동국대학교 산업시스템공학과
}

\begin{abstract}
Technology roadmap is a powerful tool that considers relationships of technology, product and market and referred as a supporting technology strategy and planning. There are numerous studies that have attempted to develop technology roadmap and case studies on specific technology areas. However, a number of studies have been dependant on brainstorming and discussion of expert group, delphi technique as qualitative analysis rather than systemic and quantitative analysis. To overcome the limitation, patent analysis considered as quite quantitative analysis is employed in this paper. Therefore, this paper proposes new technology roadmapping based on patent citation network considering technology life cycle and suggests planning for undeveloped technology but considered as promising. At first, patent data and citation information are collected and patent citation network is developed on the basis of collected patent information. Secondly, we investigate a stage of technology in the life cycle by considering patent application year and the technology life cycle, and duration of technology development is estimated. In addition, subsequent technologies are grouped as nodes of a super-level technology to show the evolution of the technology for the period. Finally, a technology roadmap is drawn by linking these technology nodes in a technology layer and estimating the duration of development time. Based on technology roadmap, technology planning is conducted to identify undeveloped technology through text mining and this paper suggests characteristics of technology that needs to be developed in the future. In order to illustrate the process of the proposed approach, technology for hydrogen storage is selected in this paper.
\end{abstract}

요 약 기술로드맵은 기술, 제품, 시장의 관계를 고려하여 기술전략 및 기획을 지원하는 강력한 도구로서 기술 로 드맵을 개발하거나 실무에 적용시킨 사례 등과 관련된 연구가 다수 수행되었다. 그러나 대부분의 기술로드맵 연구들 은 체계적이고 정량적인 분석보다는 브레인스토밍, 전문가 그룹 활용, 델파이 등과 같은 정성적인 방법에 의존하고 있다. 이러한 한계를 극복하기 위해, 본 연구에서는 대표적인 정량적 분석인 특허분석을 활용하였다. 따라서 본 연구 의 목적은 기술수명주기를 고려한 특허인용네트워크를 개발하여 기술로드맵 작성에 적용하고, 이를 통해 유망한 미 개발 기술을 기획하는 것이다. 이를 위하여, 우선 특허데이터와 인용정보가 수집되고 이를 바탕으로 특허인용 네트워 크가 작성된다. 둘째, 기술수명주기 및 특허출원연도를 고려하여 수명주기에서의 위치를 분석하고, 향후 기술개발기 간이 추정된다. 기술진화를 보여주기 위해 하위 세부기술들은 그룹핑되어 상위기술을 설명하고 이는 기술로드맵에 포함되는 노드로서 지칭된다. 마지막으로 기술 층의 각 기술 노드들을 연결 짓고 개발기간을 추정하여 기술로드맵을 작성한다. 이 기술로드맵을 바탕으로 기술기획을 수행하기 위해 텍스트 마이닝을 적용하여 미개발 기술을 제시하고, 향후 개발될 필요가 있는 기술의 특성을 제안한다. 본 연구는 수소저장 기술을 선정하여 앞에서 제시된 방법과 과정 을 설명하였다.

Key Words : Technology roadmap, Technology planning, Patent citation network, Technology life cycle, Hydrogen energy

This work is supported by basic science research program through the National Research Foundation of Korea (NRF) funded the Ministry of Education, Science and Technology (NO. 2009-0073285).

*Corresponding Author : Byungun Yoon(postman3@dongguk.edu)

Received September 29, 2011 Revised (1st October 27, 2011, 2nd November 7, 2011) Accepted November 10, 2011 


\section{Introduction}

In recent years, technology development has been rapidly accelerated and life cycle of technology and product has been gradually shortened. Moreover, investment to research and development(R\&D) activities has been quantitatively enlarged and efficiency of investment has been needed to be qualitatively improved because big successes on new technology and product make a huge profit. In this perspective, the importance of strategic technology planning is magnified and thus, technology roadmap is shed light on effective technology planning. Technology roadmap has great potentials for supporting the development and implementation of integrated strategic business considering relationships of technology, product and market[1]. It is widely used to support technology strategy and planning and adapted in a variety of industry[2].

Most studies have dealt with methods for developing technology roadmap and case studies in specific technology areas. In terms of roadmapping, most of previous researches have been dependent on qualitative analysis such as brainstorming and discussion of expert group or Delphi technique. It is considered a limitation of technology roadmapping. To overcome, patent analysis that is viewed as quite quantitative analysis is employed in this paper. Patent is referred as an ample sources of technological and economical knowledge[3]. For this reason, patent analysis makes it possible to easily acquire technology information and assess technology.

Consequently, this paper aims to propose a new technology roadmapping based on patent citation network considering technology life cycle and to suggest technology planning through text mining.

This paper is organized as follows. The important theoretical backgrounds of technology roadmap, patent analysis and text mining- are introduced in section $\Pi$. Basic concepts and overall process are explained briefly and then a methodology to develop patent citation network and technology roadmap for technology planning is described in detail in section III. In order to illustrate the proposed approach, the case of hydrogen energy storage technology is studied in section IV, and conclusions from our research and suggests directions for future studies in section $\mathrm{V}$.

\section{Background}

\subsection{Technology roadmap}

Technology roadmap explores and communicates the dynamic linkages between technological resources, organizational objectives and the changing environment. In this perspective, it is considered a powerful technique for supporting technology strategy and planning[4,5].

In particular, technology roadmap is helpful to firms because it enables firms to identify and acquire core technologies in advance, and to share technological goals and strategies in support of its long term and strategic R\&D planning[6]. Technology roadmap has a various type so that it can be customized to firms and organization for their strategic purposes. For example, a patent and service-oriented layer are added to existing technology roadmap, proposing an objective and systematic framework for devising $R \& D$ strategy of the service industry[7].

However, most of technology roadmap is basically a time-based graphical chart and is on the basis of several layers: commonly technology, product, market- nodes and links. Previous studies focused on developing technology roadmap by using qualitative analysis such as Delphi[8], brainstorming and environmental scanning[9] or dealt with case studies in specific technology areas[10,11]. Recently, several researches have been shed new light on application possibilities of technology roadmap[6].

\subsection{Patent analysis}

Patent is regarded a vital element for analyzing about technology and also referred as output of all kinds of science and technology. Analyzing patent information provides relevant information on the competitor's strategies and helps to assess the competitive potential of technologies. In addition, it is utilized to identify and assess options for the external generation of technological knowledge and also used for storing relevant knowledge as a core element of knowledge management[12].

In recent years, numerous studies have attempted to investigate patent indicators for appropriate technology life cycle development[13] and to realize life cycle of technology by employing patent statistics like the number of application and cumulative frequency of patents[14]. 
Patent citations are described as the number of citations of a patent in subsequent patent and can identify the impact of technology development and technological innovation[15]. Patent citation analysis examines citation links among different patents, and between patents and scientific literatures[16]. In the perspective of patent analysis, individual patents are presented as nodes and citation relationships between patents as arcs between nodes on the patent citation network.

\subsection{Text mining}

Data mining represents a group of algorithmic techniques which assist in detecting patterns within structured database. It is well-known as knowledge discovery from a database, however, has a limitation that is difficult to deal with a large amount of unstructured textual documents[17]. To overcome the limitations of data mining, the concept of text mining appeared. Text mining is a type of data mining related to disclosure of patterns from collections of unstructured text and applied in strategic business and patent analysis[18]. Through text mining, analyzers can find implicit, previously unknown, and potential useful patterns in a large text repository[17]. There are a lot of studies on feature extraction that identify and extract important keyword by using text mining or measure similarity between patents[3] and keyword vector. In this paper, text mining is used as information-extracting tool for technology planning.

\section{Research Framework}

\subsection{Basic concepts}

This study suggests a new technology roadmapping through patent citation network considering technology life cycle and technology planning based on technology roadmap. A majority of studies for develop technology roadmap utilize qualitative analysis such as delphi technique and brainstorming. In contrast with previous researches, patent citation analysis is used to develop technology roadmap. The analysis is applied to visualize patent citation network and then relationships among patents can be easily examined. In particular, since the main purpose in drawing the technology layer of a roadmap is to decide the duration and contents of technology development, investigation of technology life cycle and cluster analysis from patent citation information are utilized to help analysts estimate the length of time it will take to develop a technology and grasp important future technology. Particularly, undeveloped but promising technology is analyzed in detail through technology planning that suggests critical characteristics in the form of keyword with text mining.

\subsection{Overall process}

The overall process of conducting technology roadmap based on patent citation network and technology planning goes through several steps as shown Fig. 1. First of all, patent information should be collected for analyzing patents and forming a patent citation network in the next phase. Prior to develop network of patent citation, patent information is needed to be pre-processed and then apply network analysis tool. Second, a patent citation network that consists of nodes representing patents and arcs between nodes also showing relationships between patents, is developed. Third, a stage of selected technology in the life cycle is investigated, considering application year and technology life cycle. The life cycle of technology is inspected by using inner citing proportion and moving average method. Then, the lifetime of a technology is estimated to plan the duration of technology development through the technology life cycle. Next, patents on network are grouped by clustering analysis so that draw up nodes in technology roadmap. In this process, patent groups on the network are separated into meaningful or unnecessary groups through screening. After filtering out, each cluster is named after keywords composing patent groups. Finally, the technology roadmap which has two layer- technology and patent citation network can be developed through groups of patents that are arranged in chronological order. Based upon technology roadmap at the previous step, technology planning is conducted on the developing or undeveloped but promising technology using text mining. Consequently, critical keywords are suggested as the contents that represent characteristics of the promising technology. 


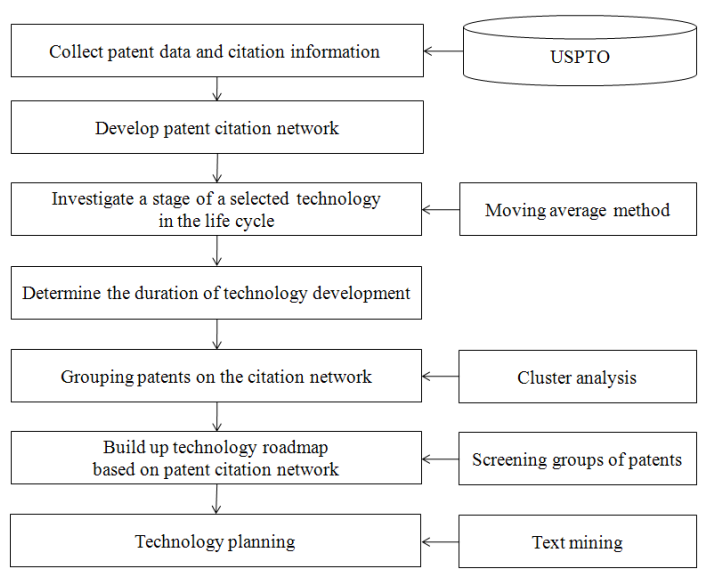

[Fig. 1] The overall process

\subsection{Developing a technology roadmap based on patent citation network}

\subsubsection{Data collection}

Patent data and citation information are used as main sources to develop a technology roadmap in this research. Patent data are collected from USPTO(United States Patent and Trademark Office) database. Searching query for collecting patent data is conducted with title of technology. Patent data is generally composed of patent number, title of invention, abstract, claims, information about citation relationships, and so on. Although all information is variable to analyze patents, application year and citation relationships are selected to develop patent citation network in roadmapping. Before developing patent citation network, relationships of patent citation are pre-processed. In order to examine whether each patent is cited or not, rows and columns of a table are set by all collected patents as shown in Table 1. If a specific patent in the column of citation table is cited by other patents in the row, the intersectional cell of citation table is represented with a "1".

[Table 1] Example of patent citation table

\begin{tabular}{|c|c|c|c|c|c|c|}
\hline & $\mathrm{P} 1$ & $\mathrm{P} 2$ & $\mathrm{P} 3$ & $\mathrm{P} 4$ & $\ldots .$. & $\mathrm{P}_{j}$ \\
\hline $\mathrm{P} 1$ & 0 & 1 & 1 & 0 & $\ldots .$. & 1 \\
\hline $\mathrm{P} 2$ & 1 & 1 & 0 & 1 & $\ldots .$. & 1 \\
\hline $\mathrm{P} 3$ & 0 & 0 & 0 & 0 & $\ldots .$. & 0 \\
\hline $\mathrm{P} 4$ & 1 & 0 & 0 & 0 & $\ldots .$. & 1 \\
\hline$\ldots \ldots$ & $\ldots .$. & $\ldots .$. & $\ldots .$. & $\ldots .$. & $\ldots .$. & $\ldots .$. \\
\hline $\mathrm{P}_{i}$ & 1 & 1 & 1 & 0 & $\ldots .$. & 0 \\
\hline
\end{tabular}

\subsubsection{Developing patent citation network}

Patent citation network is developed by using the table representing citation relationships and UCINET software, which is a social network analysis and development tool. Each node at patent citation network represents and arc between nodes denotes citations relationships between patents. For example, US5888317 is cited by US6737194, US6517970, US6210498 and US4728586 and cites US4370163 and US4160014 in fig. 2. If there are no arcs or nodes, it denotes that no relation between patents occurs at that time or that patents are not applied yet. Generally, the structure of a normal patent citation network focuses on just the linkage of nodes, the network for technology roadmapping should include on more dimension - time - because one of the most important factors in roadmapping is time. Every nodes are arranged from left to right in the chronological order so that patent evolution is produced.

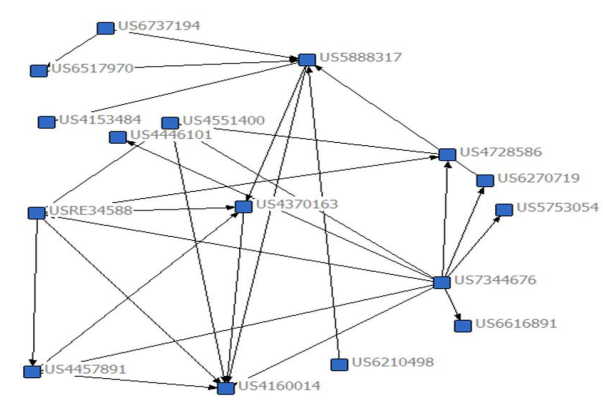

[Fig. 2] Example of patent citation network

\subsubsection{Investigating a stage of technology in the life cycle}

To investigate the technology life cycle, inner citing proportion will be proposed in this research. If the number of citing patents in a selected technology area is only considered, patents that cite other patents in other areas of citing are not regarded. From this perspective, inner citing proportion is used to examine the technology life cycle. Thus, inner citing proportion refers to the proportion of patents citing other patents in a chosen technology area among patents citing other patents in all technology areas. The concept is very useful to analyze the life cycle of a technology because a patent in an 
introduction stage tends to cite patents in other patent classifications and, on the contrary, a patent in a growth stage often cites patents in the same patent classification.

\section{Inner citing proportion $=\frac{\text { The number of citing proportion in selectedtechnologyarea }}{\text { Totalnumber of citing proportion }}$}

After calculating the inner citing proportion of each patent, the average by year is computed. Then, the moving average proportion by year is applied because there are many fluctuations if using the normal average value by year. The moving average method is normally applied with time series data to smooth out short term fluctuations and highlight longer-term trends or cycles. Based on moving average, a cutoff value should be set to determine the technology life cycle through a sensitivity analysis. Generally, the technology life cycle is separated into four stages by the cut-off value of moving average and increasing or decreasing trends. If the moving average value is higher than 0 and lower than cut-off value and shows increasing trends, it is called the "introduction stage". If the moving average is higher than the cut-off value and lower than maximum moving average value, it is called the "growth and maturity stage". At that time, if there is fluctuation during growth and maturity stage, it can be separated into growth and maturity. Finally, if the moving average is higher than 0 and lower than a cut-off value, showing decreasing trend, the technology is in the "decline" stage.

\subsubsection{Determining the duration of development}

According to the life cycle interval that is divided using the inner citation proportion and moving average method, maturity of technology and duration of technology development need to be estimated during this phase. The technology life cycle of patent is investigated to predict the duration of technology development. Comparing the current point of technology development at the selected technology life cycle with the time point of the existing patent application, the duration of technology development can be estimated. By utilizing the patent life cycle, the technology life cycle and the duration of technology development is forecasted. However, this approach is hard to apply to plan technology development after current patent application because the proposed method utilizes patent information and patent application is ascertained through long-term planning. Fig. 3 shows the mechanism to determine technology development duration through roadmapping.

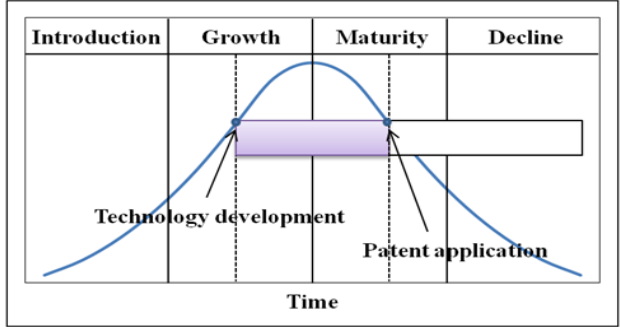

[Fig. 3] The mechanism to determine duration of technology development

\subsubsection{Grouping patents}

Patents on the network need to be grouped by cluster analysis to draw up nodes in the technology roadmap. The groups of patents can be used to devise important technologies and links among them (nodes in the technology layer). Though there are many methods for grouping, the average similarities between all pairs is applied to group patents by using UCINET in this research. In particular, clusters that are composed of only one patent may emerge when patents are grouped through cluster analysis and need to be filtered out. A definitive cluster, which means a grouped and filtered-out cluster, consists of connected nodes on a technology roadmap that are named after keywords and features that stand for individual clusters.

\subsubsection{Developing a technology roadmap}

Important elements comprising technology roadmap are nodes, time, and layers. Although the layer of a technology roadmap are generally composed of technology, product, and market, two layers(technology and patent citation network) are featured in this research. Each node on a technology roadmap is made up of a grouped cluster of patents, as explained in section 3.3.5., and is arranged in chronological order of patent application. Time is determined by duration of technology 


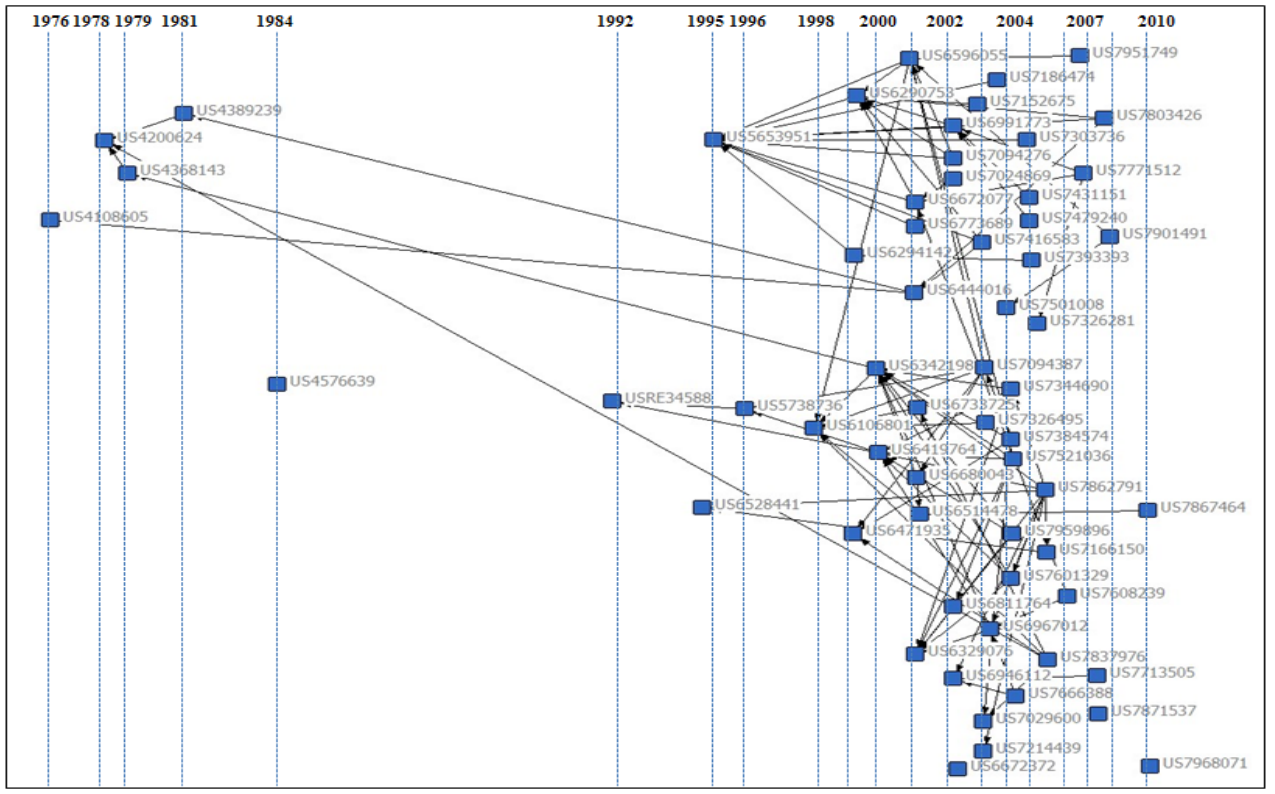

[Fig. 4] Patent citation network

development and duration is represented by the length of technology nodes. Consequently, a technology roadmap is drawn by connecting these technology nodes in a technology layer and patent citation network.

\subsubsection{Technology planning}

Technology nodes on technology roadmap developed at previous step are categorized three types, which are (1) developed technology in the past, (2) developing technology at this time and (3) undeveloped but promising technology in the future. Technology planning is conducted to (2) developing and (3) undeveloped but promising technology in the future through text-mining. The categorization of technology nodes will be processed by literature review such as existing roadmap, research paper. Full-text of patent documents is used for text mining because it contains much more information about technology than abstract and title part of patent. Based on full-text patent documents, critical keywords for technology planning are extracted using a text-mining tool, TextAnalyzer. In this paper, the characteristics of technology that will be necessary to develop in the future are suggested at the contents of the technology layer.

\section{Results}

\subsection{Data}

In order to illustrate the proposed method, the storage for hydrogen energy-related technology is chosen. A hydrogen energy system is mainly separated production, delivery, storage, conversion and end-use applications, that are closely interrelated and interdependent[19]. Among those, hydrogen storage- related technology such as method for storage, the components of hydrogen devices become considered as critical because it is difficult to store hydrogen at any container or using storage method. In this study, 427 hydrogen storage related-patents applied from 1972 to 2010 are collected from USPTO database. For retrieving relevant patents, 'hydrogen storage' is utilized as the searching query.

\subsection{Development of patent citation network}

As shown in Fig. 4, a patent citation network based on patent information is developed in the chronological order. Each patent is depicted nodes at patent citation network and citation relationships are denoted arcs between nodes at patent network. In this paper, patents that are relevant to core technology of hydrogen storage 
are illustrated at patent citation network because it might be complex if too much collected data are arranged.

\subsection{Development of technology roadmap}

Generally, technology roadmap is composed of three layer - technology, product, and market. However, the proposed roadmap consists of two layer - technology and patent citation network. In order to connect the patent citation network layer and technology layer, patents on the network were grouped by hierarchical clustering analysis and were derived 16 clusters on the basis of the citation network. Even though a number of clusters were extracted because of much patent data, clusters were composed only one patent, which means that there are no relationships between patents, are filtered out. Then, keywords that are able to stand for each cluster were extracted in the 'abstract' part of patent documents. The portion of grouping patent and keywords representing each cluster is able to be identified in Table 2 .

The title of technology nodes on the technology roadmap is needed to be defined, considering characteristics of individual clusters, thus, it was entitled by keywords representing each group of patents. For instance, cluster 5 contains "hydrogen storage", "storage materials" and "metal hydride", and the title of node is named "Metal- hydride hydrogen storage system". Definitive title of nodes on a technology roadmap will be shown as Table 3.

[Table 2] Patent groups and their keywords

\begin{tabular}{|c|c|l|l|l|}
\hline \multirow{2}{*}{ Keywords } & \multicolumn{1}{|c|}{ Cluster 4 } & \multicolumn{1}{c|}{ Cluster 5 } & Cluster 8 & Cluster 9 \\
\cline { 2 - 5 } & $\begin{array}{l}\text { Hydrogen storage } \\
\text { polymeric material } \\
\text { storage alloy }\end{array}$ & $\begin{array}{l}\text { metal hydride } \\
\text { container } \\
\text { cryosorptive }\end{array}$ & $\begin{array}{l}\text { aluminum hydride } \\
\text { composition } \\
\text { dehydrogenated }\end{array}$ & $\begin{array}{l}\text { carbon material } \\
\text { absorption } \\
\text { medium }\end{array}$ \\
\hline The number of patents & 43 & 32 & 36 & 27 \\
\hline
\end{tabular}

[Table 3] Title of nodes on the technology roadmap

\begin{tabular}{|l|l|}
\hline Cluster & \\
\hline Cluster 1 & Title of nodes \\
\hline Cluster 2 & Hydrogen storage systems utilizing Zr \\
\hline Cluster 3 & Silicon surface of hydrogen storage tank \\
\hline Cluster 4 & Polymeric material consisting of surface for hydrogen storage container \\
\hline Cluster 5 & Metal-hydride hydrogen storage system \\
\hline Cluster 6 & Economic materials for hydrogen storage \\
\hline Cluster 7 & Supporting systems \\
\hline Cluster 8 & Aluminum- hydride hydrogen storage system \\
\hline Cluster 9 & Hydrogen storage using carbon materials \\
\hline Cluster 10 & The structure and elements for hydrogen storage container \\
\hline Cluster 11 & Supply-release valve comprising hydrogen storage tank \\
\hline Cluster 12 & Hydrogen absorbing alloy \\
\hline Cluster 13 & Electrochemical materials for hydrogen storage and hydride electrodes \\
\hline Cluster 14 & Alkaline storage battery including activated materials \\
\hline Cluster 15 & $\begin{array}{l}\text { Hydrogen storage alloy } \\
\text { Process for producing hydrogen storage alloy }\end{array}$ \\
\hline Cluster 16 & Powder composing storage alloy \\
\hline
\end{tabular}


[Table 4] Life cycle of hydrogen energy storage

\begin{tabular}{|l|l|}
\hline \multicolumn{1}{|c|}{ Stage } & \multicolumn{1}{c|}{ Criteria } \\
\hline Introduction & $0<$ Moving average $<0.35$, increasing status from 0 to 0.35 \\
\hline $\begin{array}{l}\text { Growth } \\
\text { Maturity }\end{array}$ & $\begin{array}{l}\text { i) } 0.35<\text { moving average }<\text { maximum value of moving average } \\
\text { ii) the time of a great fluctuation is set by standard that separate growth stage and maturity stage }\end{array}$ \\
\hline Decline & $0<$ moving average $<0.35$, decreasing status from 0.35 to 0 \\
\hline
\end{tabular}

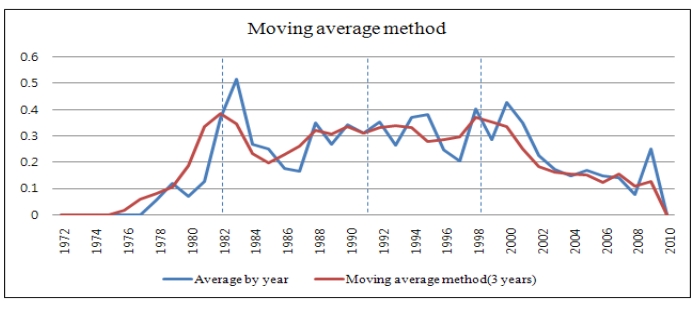

[Fig. 5] The technology life cycle in hydrogen storage

Fig. 5 presents the moving average of inner citing proportion of 'hydrogen energy storage' related- patents. Based on this figure and a cut-off value that was determined through sensitivity analysis, life cycle of hydrogen energy storage is able to estimated. In this step, sensitivity analysis is employed to decide the cut off value which is able to trade off sparse part against dense part in the technology life cycle and is attempted to visualize more effectively. Several kinds of values, which are $0.25,0.30,0.35,0.40,0.45$, are supposed to examine cut off value and sensitivity analysis is conducted. As a result, the cut-off value was set 0.35 and the criteria separating stages of technology life cycle are defined as shown Table 4. Based on the criteria, introduction stage of technology life cycle in the hydrogen energy storage may be identified from 1972-1982, the growth stage from 1983-1991, the maturity stage from 1992-1998 and the decline stage from 1999-2010. The average life cycle of hydrogen energy system is analyzed to estimate technology development duration. Consequently, the interval of introduction stage is 11 years, the growth stage is 16 years, the maturity stage is 14 years and the decline stage is 8 years.

As a consequence, a technology roadmap is drawn by considering patent citation network and useful information on the duration of technology development and nodes of technology. At first, nodes on technology are comprised of patent groups by hierarchical clustering analysis on the patent citation network. Each node is arranged in the chronological order considering duration of technology development. After arranging patents, it is linked to corresponding nodes of technology. For example, "Aluminum-hydride for hydrogen storage" in Fig. 6, is 5 years at the maturity stage, which means technology development duration is 14 years, thus, this node is mapped until 2025. "Hydrogen storage using carbon materials", mapped until 2036, is 3 years into the growth stage, which presents that duration of technology development remains 25 years.

\subsection{Technology planning}

Among technology nodes, a "Hydrogen storage using carbon materials" node is chosen to design because it has been developed since 1997 and consistently developing at this time. Patents corresponding "Hydrogen storage using carbon materials" were classified as developed and undeveloped. Through text mining about undeveloped patents, 10 keywords that have the criteria of word and compound were extracted in the order of frequency. Consequently, as presented in Table 5, technology development for hydrogen storage will be concentrated on using carbon materials and nanostructured elements.

[Table 5] Keywords on 'hydrogen storage using carbon materials' node

\begin{tabular}{|c|l|l|}
\hline Criteria & \multicolumn{1}{|c|}{ Word } & \multicolumn{1}{c|}{ Compound } \\
\hline \multirow{5}{*}{ Keyword } & $\begin{array}{l}\text { hydrogen } \\
\text { storage } \\
\text { material } \\
\text { carbon } \\
\text { gas } \\
\text { metal } \\
\text { temperature } \\
\text { pressure } \\
\text { surface } \\
\text { container }\end{array}$ & $\begin{array}{l}\text { hydrogen storage } \\
\text { storage material } \\
\text { carbon material } \\
\text { hydrogen absorbing } \\
\text { metal hydride } \\
\text { storage container } \\
\text { nanostructured storage } \\
\text { microtubular elements }\end{array}$ \\
\hline
\end{tabular}


Carbon materials are employed as mediums for storing hydrogen at low temperature and researches on carbon nanostructures have been showing possibilities in terms of absorbing hydrogen at surface of carbon. Carbon nanotube also might be infer a promising field for hydrogen storage based on keywords 'carbon material' and 'microtubular elements'. In fact, carbon nanotube comes into the spotlight in that it shows very surprising high hydrogen storage capacity[20,21].

\section{Conclusions}

The main objective of a proposed approach is to propose a new technology roadmapping and technology planning based on technology roadmap. First of all, a new technology roadmapping approach is developed on the basis of patent citation network through several steps using patent and citation information. The duration of technology development considering technology life cycle is estimated for the purpose of satisfying time, which is considered as one of the important elements comprising technology roadmap. The other elements, layer and nodes, also investigated through quantitative analyses. Then, technology on hydrogen energy storage is applied to elucidate the process of suggested approach.

Secondly, developing at the present or undeveloped technology is analyzed through text mining and the keywords implying characteristics of promising technology areas are extracted at the contents of technology level. The results of suggested approach can be evaluated quantitative and systematic roadmapping approach. Therefore, this paper is distinguishable from existing studies. While the work of Yoon and Park [3] utilized keyword vectors to develop a patent network, the proposed approach in this research applied patent citation information, adding the dynamic dimension of patent application. Moreover, the approach provides the future trends of technology with emerging keywords, enabling this paper to be differentiated from the previous research of Jeong and Yoon that just drew a technology roadmap [22].

Nevertheless, there are also some limitations and additional research is needed to elaborate the framework of this research. First, keywords in technology planning can be outlined about technology because they are extracted from a text mining tool. Additional literature review concerning relevant technology is needed to elaborate and provide detailed contents for technology.

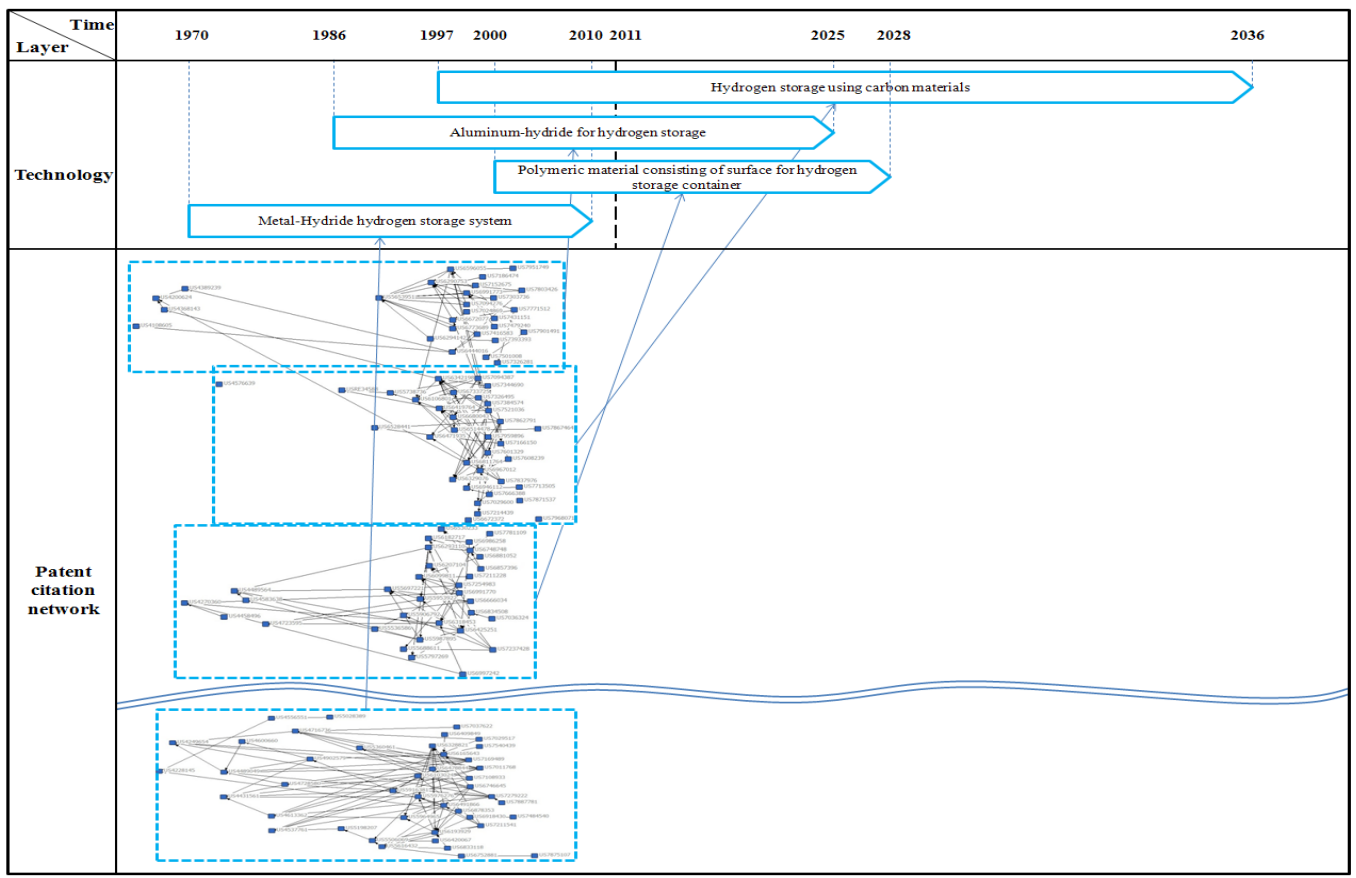

[Fig. 6] Technology roadmap based on patent citation network 
Second, it is difficult to plan and represent emerging technology on the technology roadmap based upon patent citation network. Because this study takes advantage of patents that applied until now, only technology nodes corresponding patent groups already applied can be depicted at technology roadmap. In this point of view, future research allowing for emerging patent and technology will be accomplished by virtue of the concept of patent roadmap.

\section{References}

[1] R. Phaal, C.J.P. Farrukh, D. R. Probert, "Technology roadmapping - A planning framework for evolution and revolution", Technological Forecasting and Social Change, Vol. 71, pp.5-26, 2004.

[2] EIRMA, "Technology Roadmapping", Working group report, European Industrial Research Management Association, Paris, Vol. 52, 1997.

[3] B. Yoon and Y. Park, "A text-mining-based patent network: Analytical tool for high-technology trend", Journal of High Technology Management Research, Vol. 15, pp.37-50, 2004.

[4] D. Fenwick, T. U. Daim, N. Gerdsri, "Value Driven Technology Road Mapping(VTRM) process integrating decision making and marketing tools: Case of Internet security technologies", Technological Forecasting and Social Change, Vol. 76, pp.1055-1077, 2009.

[5] University of Cambridge, T-Plan: the fast start to technology roadmapping, 2001.

[6] S. Lee, S. Kang, YS. Park, Y. Park, "Technology roadmapping for R\&D planning: The case of the Korean parts and materials industry", Technovation, Vol. 27, pp.443-445, 2007.

[7] J. Suh and S. Park, "Service-oriented Technology Roadmap(SoTRM) using patent map for R\&D strategy of service industry", Expert Systems with applications, Vol. 36, pp.6754-6772, 2009.

[8] K. Czaplicak-Kolarz, K. stanczyk, K. Kapusta, "Technology foresight for a vision of energy sector development in Poland till 2030: Delphi survey as an element of technology foresighting", Technological Forecasting and Social Change, Vol. 76, pp.327-338, 2009.

[9] C. Kim, H. Kim, S. Han, C. Kim, M. Kim, S. Park, "Developing a technology roadmap for construction R\&D through interdisciplinary research efforts",
Automation in Construction, Vol. 18, No. 3, pp.330-337, 2009.

[10] S. Harrell, T. Seidel, B. Fay, "The National Technology Roadmap for Semiconductors and SEMATECH future directions", Microelectronic Engineering, Vol. 30, No. 1-4, pp.11-15, 1996.

[11] C. Gough, S. Mander, and S. Haszeldine, "A roadmap for carbon capture and storage in the UK", International Journal of Greenhouse Gas Control, Vol. 4, No. 1, pp.1-12, 2010.

[12] H. Ernst, "Patent information for strategic technology management", World Patent Information, Vol. 25, pp.233-242, 2003.

[13] R. Haupt, M. Kloyer, M. Lange, "Patent indicators for the technology life cycle development", Research Policy, Vol. 36, pp.387-398, 2007.

[14] C. V. Trappey, H. Wu, F. Taghboni-Dutta, A. Trappey, "Using patent data for technology forecasting: China RFID patent analysis", the ASME 2009 International Manufacturing Science and Engineering Conference, Indiana, USA, 2009.

[15] Y. Park, B. Yoon, S. Lee, "The idiosyncrasy and dynamism of technological innovation across industries", Technology in Society, Vol. 27, pp.471 $-485,2005$.

[16] I. Wartburg, T. Teichert, K. Rost, "Inventive progress measured by multi-stage patent citation analysis", research Policy, Vol. 34, pp.1591-1607, 2005.

[17] A. M. Dias, C. G. Mansur, M. Myczkowski, M. Marcolin, "Whole field tendencies in transcranial magnetic stimulation: A systematic review with data and text mining", Asian Journal of Psychiatry, Vol 4, pp.107-112, 2011

[18] U. M. Fayyad, G. Piatetsky-Shapiro, P. Smyth, R. Uthurusamy, "Advances in knowledge discovery and data mining, AAAI Press, 1996

[19] United States Department of Energy, "National Hydrogen Energy Roadmap", 2002.

[20] S. No, Y. Rhee, K. Kang, S. Choi, J. Kim, "Technology Characteristics of Hydrogen Storage and Its Technology Trend by the Patent Analysis", Trans. of the Korean Hydrogen and New Energy Society, Vol. 19, No. 1, pp.90-102, 2008.

[21] H. Cheng, Q. H. Yang, C. Liu, "Hydrogen storage in carbon nanotube", Carbon, Vol. 39, No. 10, pp.1447-1454, 2001.

[22] Y. Jeong and B. Yoon, "Technology Roadmapping 
Based on Patent Citation Network Considering Technology Life Cycle", IEEE-International Technology Management Conference, San Jose, CA USA, 2011.

\section{Yujin Jeong}

[Associate member]

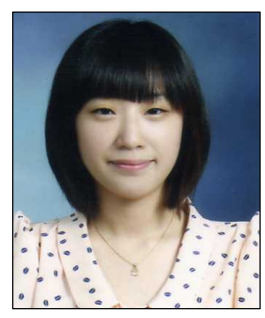

- Mar. $2008 \sim$ current : Dongguk Univ, Dept. of Industrial \& Systems Engineering, Undergraduate course

- May. $2010 \sim$ current : Dongguk Univ. Technology Management Laboratory, Researcher

$<$ Research Interests $>$

Technology and patent planning, R\&BD(Research \& Business Development)

\section{Byungun Yoon [Regular member]}

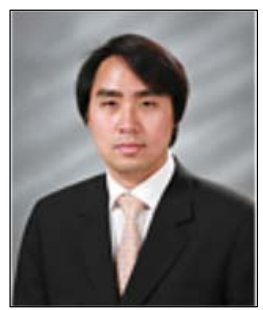

- Feb. 2000 : Seoul National Univ, MS

- Feb. 2005 : Seoul National Univ. PhD

- May $2006 \sim$ Mar. 2007 : Univ. of Cambridge, Visiting Scholar,

- Mar. $2007 \sim$ current : Dongguk Univ. Professor

$<$ Research Interests $>$

Patent Analysis, Technology Roadmap, Technology Intelligence, Technology Forecasting 